\title{
Padilla, Ignacio (2010), La isla de las tribus perdidas : la incógnita del mar latinoamericano, Barcelona-México: Random House Mondadori.
}

\section{Proemio}

E bicentenario de las independencias latinoamericanas ha ofrecido, al igual que hace algunos años el V centenario del descubrimiento, la oportunidad para que diversos grupos sociales mostraran inflamadas posiciones políticas en torno a la celebración, a la revisión histórica o a la resistencia y rechazo a eventos que se han significado por el despilfarro "oficial" y el reconocimiento de que hay, quizás, poco que celebrar. Por su parte, para las Ciencias Sociales y las Humanidades, dicha fecha, adelantada por los agentes políticos centrales al inicio y no a la consumación, ha sido motivo para la revisión —crítica o apologética - del proceso, así como para reposicionar una vieja pregunta que refleja, al tiempo, una igualmente arcaica utopía: qué define la identidad latinoamericana.

El ejercicio devela un carácter revisionista: busca entender dónde se perdió el rumbo que aleja a nuestros países de los ideales del desarrollo y la modernidad occidentales. Muy a menudo se dejan entrever las particularidades que resaltan aquello que nos disocia: caudillos locales e ideologías nacionalistas. No obstante, con ello el gran enigma de la identidad latinoamericana no ha sido desvelado y pareciese que, tal como afirmó
Pratt en "Modernidades, otredades, entre-lugares" (Desacatos, núm. 3, 2000):

\begin{abstract}
Nuestra capacidad para reflexionar sobre nuestras realidades e historias - y de ahí nuestra capacidad de fundar visiones sociales y culturales basadas en nuestras propias realidades e historia - continúa siendo dificultada por el peso y la fuerza de los discursos sobre la modernidad difundidos desde Europa.
\end{abstract}

Aunque no busca directamente en los discursos de la modernidad occidental, sino en fragmentos de la historia y del llamado "boom" de la literatura latinoamericana (cuento y novela, excluyendo a la poesía), La isla de las tribus perdidas. La incógnita del mar latinoamericano de Ignacio Padilla, es la confirmación de aquella regla enunciada por Pratt. El ensayista rastrea en 204 páginas y nos orienta entre los procelosos mares de su interpretación del "enigmático divorcio entre América Latina y el Mar" en cinco bitácoras - a guisa de capítulos-. Dicha experiencia, que califica de "gatuperio" y aplica por extensión a ríos, lluvias, tormentas, diluvios, naufragios, inundaciones, es la pauta que retoma para "vertebrar una perspectiva más clara del ser latinoamericano". 


\section{El contenido de la obra}

"La espada innumerable del mar" es la primera bitácora en alusión a Jorge Luis Borges, para quien la magia de mar entre los amantes es "melancólica singladura 'una espada innumerable y una plenitud de pobreza"'. Aquí recuerda la declaración de Bolívar en plena gesta independentista: "si se opone la Naturaleza, lucharemos contra ella y haremos que nos obedezca", para afirmar que dicha promesa no se cumplió y, en interpretación del autor, aquello que aprehendemos como muestra de la entereza de El Libertador, en realidad era un gesto de impotencia ante una naturaleza que ya era en aquel período de nuestra historia imaginada, paradójicamente, como cuerno de la abundancia e indomeñable.

La literatura, entonces, es el instrumento para encontrar "belleza en la sensación de fragilidad que nos transmite la grandeza del incontrolable monstruo natural" que se manifiesta en todo tipo de desproporción. Este monstruo, metáfora de Latinoamérica, es "multiplicidad que niega la unidad, el gigantismo o el enanismo que niegan la mesura, la rabiosa movilidad o el extremo quietismo opuestos al arrullo pausado". En ese sentido, la navegación termina en "naufragio o en cataclismo, en desembarco intempestivo o en desencanto". No obstante, nuestra relación con las aguas termina 'anegada'; se convierte en pantano que «nos apresa y paraliza como en una borrachera»; pero también es 'negada' para convertirse en árido desierto, un "mar de polvo" como en las obras de García Márquez y Juan Rulfo.

El segundo capítulo o bitácora, "Huracanes ciegos y laberintos de agua", está dedicado a la lluvia y nos recuerda "uno de los axiomas más citados de García Márquez: 'La imaginación es un lugar donde llueve". Ratifica así que nuestras letras son un lugar donde no ha escampado y, al igual que la mar, las precipitaciones pluviales tienen mucho de perversa metáfora, pues, en la literatura latinoamericana, la fuerza del agua procede con lentitud; siempre llueve, despacio pero sin pausa y, por ello, "no necesita convertirse en huracán para ser aborrecida". No se convierte en componente para germinar la semilla, al contrario, "desquicia mentes, cierra veredas en la selva, desmonta el tiempo, pierde a los hombres en su laberinto, los persigue en su lerdo peregrinar hacia la muerte" como nos ilustra la obra de García Márquez y Vargas Llosa.

El encierro que sigue a la lluvia provoca que, al igual que el anónimo coronel de García Márquez, el latinoamericano se regodee en sus fracasos. No podría ser de otra manera, como en la narrativa de Rulfo, la lluvia desatada "va creciendo en los ríos, nos arrastra hacia donde no quisiéramos o arrastra hasta nosotros lo que podría dañarnos" $y$, al igual que en la obra de Julio Cortázar, "no hay aquí una explicación a la mudanza de emociones". Ese caos, con presencia o ausencia de agua, es exacerbación de la vitalidad y exuberancia para así aumentar, por contraste, nuestra fragilidad.

En esta bitácora el autor reafirma lo que adelantó - como por accidente - en la anterior: la ciudad en estas latitudes no es un refugio, es amenaza concordada de la naturaleza. En Onetti encuentra a "la urbe latinoamericana por excelencia», donde el agua «se traduce en conflicto, ahogamiento y disimulo [...] como la alegoría del acabamiento que sobre los espíritus tiene la existencia". Por ello, en América Latina todo proyecto junto al mar está condenado al fracaso, ya que estamos "lejos de armonizar con los elementos, más aún de rebelarse contra ellos". Por ello, los diluvios de Fernando Vallejo representan no sólo el naufragio de Colombia, sino el de América Latina.

Afirma, para cerrar esta bitácora, que "La escampada en América Latina no es un alivio: es la clama chica, la silenciosa premonición de que algo terrible, peor que la tormenta, está por ocurrir". Por eso, "Errancia, tormenta, accidente: éstos son los vectores que se conjugan para el nacimiento de nuestra idea de la tierra que pisamos" y de ahí se desprende nuestra tremenda pasividad.

"Buques fantasmas y balsas de locos" es la bitácora de nuestra condena a la navegación fluvial y al 
naufragio. Ahí el autor observa que en nuestras letras e historia escasean las embarcaciones gloriosas o las armadas egregias, en cambio, abunda el barco enterrado; "emblema del fracaso de lo racional ante la fuerza siempre superior del instinto", que se prolonga al nacimiento mismo de la embarcación. El astillero rioplatense de Onetti "es una Comala costera" y como en la obra de Revueltas la barca es prolongación del infierno. En América Latina, los "barcos sirven para trasladar cautivos hacia prisiones aún más terribles, o para conducir hacia su muerte a marinos que nunca se hallaron bien en tierra". Mientras que García Márquez y Onneti trazan en dicha relación la decadencia colectiva, Álvaro Mutis bosqueja el epítome de ella, como un asunto individual y signo de la "extinción sexual y sensual".

En América Latina la embarcación no lleva a puerto seguro, nos "vomita en tierra", pues se cumple el aforismo de "origen es destino". El conquistador, al deshacerse de sus naves, determina que no hay vuelta atrás y, desde entonces, nuestro continente ha vivido "De espaldas al mar [...] con un litoral inmenso pero sin tradición marítima [... donde sólo hay] barcos piratas, balsas a la deriva y ballenas de artificio encalladas en la arena". Los aforismos populares "Quemar las naves" y "estar en el mismo barco", son parte del imaginario latinoamericano. Y, por un lado, el primero ilustra "la síntesis de una persona decididamente aferrada a la tierra y confrontada con las olas", mientras el segundo "no es un signo de solidaridad sino de fatalismo".

La Comala costera es para Padilla la premonición del "desastre de la explotación petrolera en buena parte del continente". Pero no es la única, Xochimilco representa un "trayecto que no conduce a ninguna parte". Bioy Casares dice que "cualquier camino es bueno si no sabemos hacia dónde vamos" o pretendemos saberlo sobre una balsa: "cáscara de nuez que es menos piloteada por los hombres que entregada a la voluntad de las corrientes y los vientos" para alcanzar el sueño americano. En consecuencia, "el bracero y el balsero bajan la cabeza en el río Bravo o en el mar Caribe", como un signo más de la imposibilidad de salir de nuestra situación.

El cuarto capítulo, "El signo de Jonás", es la bitácora que recalca la falta de madurez latinoamericana. Si Jonás pasa por el vientre de la ballena como rito iniciático para cumplir obediente su labor profética, la literatura latinoamericana refleja "las incontables paradojas y absurdos sobre los que se sembraron los cimientos del Nuevo Mundo" a través de "selvas que engullen, ríos que arrastran, tierras que se abren como bocas inmensas" pero que, contrario a las experiencias del personaje bíblico, sólo sirven para aniquilar y ratificar nuestra fragilidad.

En nuestras letras, la incapacidad para relacionarnos con el océano se identifica a través del relato del escritor José Luis González sobre "su niñez pesquera y puertorriqueña" con una ballena encallada y que "incapaces de entender y optimizar el portentoso regalo de las aguas, los taimados pescadores del Caribe abandonaron a su suerte aquella masa de huesos, grasa y carne". Argumento semejante, por cierto, al cuento Los trabajos de la ballena del literato chiapaneco Eraclio Zepeda, pero que ratifica a través de su simbología - todo cabeza, todo boca, monstruo-infierno-, la validación de una relación de identidad: "el mar es el monstruo, y el monstruo el mar", imagen que nos obliga a vivir tierra adentro, pero entre pantanos y selvas donde no hay firmeza posible.

La quinta bitácora titulada "Un archipiélago de soledades" no puede ser más ilustrativa de una de las características centrales que identifica Padilla en el "ser latinoamericano" y la referencia obligada es, desde luego, El laberinto de la soledad de Paz, quien conjuga "dos ideas ubicuas en toda descripción del ser latinoamericano". En nuestras letras abundan las alusiones explícitas y metafóricas a la insularidad del gobernante que tiene raíces ibéricas en la Barataria de Sancho Panza - Cervantes - y muestra su frondosa 
cauda en la Santa María de Tierra Firme de Santos Banderas - Valle Inclán-. La novela de la dictadura es, para Padilla, el género latinoamericano por excelencia. Valle Inclán, Roa Bastos, García Márquez, Rulfo, Bioy Casares, Jorge Ibargüengoitia son literatos que ilustran la condición del caudillo y del dictador latinoamericano "de moral ambigua, muertos en vida, fantasmas que no saben que son fantasmas, fugitivos carcomidos por la enfermedad o el escrúpulo o el poder". Macondo, Santa María o Comala dejan de ser lugares geográficos, son modelos de la "robinsonada latinoamericana". La isla es una alegoría de una condición existencial asociada, principalmente, al personalismo político con una "fuerte dosis de soledad narcisista y sanguinaria".

En nuestra historia, la malhadada referencia a las islas nos lleva a dos situaciones: por un lado, asumimos "sin más los contrastes que le imponen la orografía y el clima” que dificultan sobremanera la comunicación, condenándonos a la imposibilidad del sueño bolivariano o, siquiera, el de la unidad centroamericana, planteada por Manuel Arce en 1824, pues los sueños de cohesión se topan -invariablemente- con el individualismo y el caudillismo. Por otro lado, las islas reales representan lo peor del continente: refugio de piratas, presidios y fuente de conflictos entre los Estados latinoamericanos; así como "puerto de llegada de un extranjero agresor [...y] enclave del imperio colonial".

Vivimos la experiencia del exilio en nuestra propia tierra, somos pésimos emigrantes, no sabemos acomodarnos a nuevas situaciones y nuestro patriotismo imposta nuestra nostalgia a un origen que, en realidad, abominamos. En consecuencia, el latinoamericano es una persona-isla, es un ser que se resigna a su aislamiento en este mundo hiperconectado y que sigue mostrando su inclinación y necesidad de líderes mesiánicos que pongan un poco de orden. En suma, el "agua que baña la isla y la soledad que rodea al náufrago tienen la misma carga catastrófica: la una en su plenitud exteriorizante y la otra en su invitación a la introspección".

\section{El "ser latinoamericano", según Padilla}

¿Cuáles son, entonces, las marcas identitarias del ser latinoamericano? Para Padilla, la "ciudad letrada latinoamericana" nos deja los siguientes rasgos de una identidad colectiva que se encuentra lejos de generar sentimientos de comunidad. Por principio, el disenso con la naturaleza, la cual hemos sido incapaces de domesticar. Por ello, pervive una visión animista en la cual esa naturaleza está dotada de una voluntad que nos es hostil pero, sobre todo, a la que no podemos vencer.

Al no poder domesticar a la naturaleza, ésta se convierte en el eje de nuestra cultura del obstáculo, cuyas raíces se encuentran en el descubrimiento mismo del continente; el cual fue por "azar, o peor aún, por descuido", pues se experimentaba un posible tránsito a Oriente y, desde entonces, se ha buscado" "antes atravesar esta tierra que instalarse en ella”. Lo anterior conduce a la insularidady a confirmar que somos tribus, donde el aislamiento se identifica con lo agreste y lo salvaje, en antítesis a la civilización. Padilla observa que en los procesos de independencia, en el pasado, y en las actuales tentativas de crear bloques comerciales, "La dispersión triunfa una y otra vez sobre los sueños bolivarianos de unidad".

Esa dispersión carece de rumbo, por ello, considera el ensayista, que la errancia o inclinación a la deriva es uno más de los caracteres grabados en nuestra identidad y nuestra marca secular es el nomadismo. El quinto y último aspecto que identifica es la vocación de náufragos; del cual afirma es, al tiempo, epitafio. Los esfuerzos de cambio en América Latina tienen como destino el fracaso. La conclusión es contundente: "más separados por sus semejanzas que unidos por sus diferencias, los latinoamericanos hemos acusado siempre una vocación por el aislamiento en la proximidad". 


\section{A guisa de exhorto a la lectura}

La tarea de identificar los caracteres que definen al "ser latinoamericano" no es menor y, podemos estar de acuerdo o no, la propuesta de Padilla no deja de ser de gran provecho. Los lectores, el público en general interesado en las letras latinoamericanas, encontrarán en este libro una interpretación suigeneris de aquello que los autores de cuentos y novelas quisieron "retratar" de la esencia de los seres que habitan estas tierras. Mientras, el lector versado en las Humanidades y las Ciencias Sociales, interesado en la identidad de esta vasta región que llamamos Latinoamérica, encontrará elementos para concordar y para polemizar con la interpretación ofrecida por el autor.

Así, por ejemplo, lo que bien podría ser la conclusión del libro, el puerto de llegada, se presenta como punto de partida. El lector no puede colegir si Padilla se adentra o se sale de los procelosos mares de la particular interpretación por la que pretende guiarnos, o en realidad se trata de otro naufragio de nuestras letras que también muestra su renuncia al mar. En todo caso, nos ofrece una "brújula de cinco puntas", una interpretación que afirma partir de la "ciudad letrada latinoamericana" y, no obstante, presenta la estructura de la épica bíblica —desde su génesis a su apocalipsis, pasando por la necesaria búsqueda de una tierra prometida - para reiterar cinco características esenciales no del ser latinoamericano, sino, tal como lo consigna el título de la obra, de las "tribus latinoamericanas" que para el autor no logran llegar al lugar y el tiempo que marca la modernidad occidental.

Esto me lleva a dos observaciones. Por un lado, como revisión a la "ciudad letrada" se extraña que se mencione de manera iterativa que los seres de estas latitudes se ocultan tras la máscara del jolgorio, el bochinche, el carnaval y la chácara, mas no se adentre en la revisión de la obra que aborda la picaresca y el carnaval. Por otro lado, como ensayo, me parece una limitada interpretación a una propuesta antropológica de un robusto trasfondo teórico, como la de Marc Augé en Los "no lugares". Espacios del anonimato. Una Antropología de la sobremodernidad (2000), y nos muestra la ausencia de la obra antropológica que aborda el dilema latinoamericano desde el análisis del carnaval, como la de Roberto Da Matta en Carnavales, malandros y héroes. Hacia una sociología del dilema brasileño (2002).

Quizás debido a dichas ausencias podemos fácilmente observar que la propuesta de Padilla sobre el ser latinoamericano enfatiza una perspectiva pesimista en la que el barco-persona y la navegación-existencia son las metáforas de nuestra autoidentificación como seres errantes, inestables, erráticos. Características y entendimiento que bien podrían arrojar luces sobre las razones de un comportamiento tan sistemático, de una "democracia que no resuelve, de la ideología que no echa raíz”, de un Estado débil y un marco institucional que no funciona.

La riqueza que se derive de este probable debate para explicar los múltiples dilemas a los que se enfrentan las sociedades latinoamericanas hoy, sin soslayar las perspectivas como la de Padilla, será un aporte de interés en el marco de —como Padilla las llama- "chifladuras" del bicentenario y más allá de una "celebración" que sigue dejando una amarga huella.

Luis Rodríguez-Castillo PROIMMSE-UNAM-IIA 